\title{
Developmental Origins of Health and Disease: the relevance to developing nations
}

\author{
Mirembe Mandy ${ }^{1, *}$ and Moffat Nyirenda ${ }^{1,2}$ \\ ${ }^{1}$ Medical Research Council/Uganda Virus Research Institute Uganda Research Unit on AIDS, P Box 49, Entebbe, Uganda; \\ ${ }^{2}$ London School of Hygiene \& Tropical Medicine, Keppel Street, London WC1E 7HT, UK \\ *Corresponding author: Tel: +256752662773; E-mail: Mandy.Wilja@mrcuganda.org
}

Received 4 January 2018; editorial decision 11 January 2018; accepted 22 January 2018

\begin{abstract}
Low- and middle-income countries (LMICS), particularly those in sub-Saharan Africa, are experiencing rapid increases in the prevalence of non-communicable diseases (NCDs), which may not be fully explained by urbanization and associated traditional risk factors such as tobacco smoking, excessive alcohol consumption, poor diet or physical inactivity. In this commentary, we draw attention to the concept of Developmental Origins of Health and Disease (DOHaD), where environmental insults in early life can contribute to long-term risk of NCDs, the impact of which would be particularly important in LMICs where poverty, malnutrition, poor sanitation and infections are still prevalent.
\end{abstract}

Keywords: Developmental origins of health and disease, Early-life, Low- and middle-income countries, Manutrition, Non-communicable diseases, Risk factors, Sub-saharan Africa

\section{The concept}

The 'Developmental Origins of Health and Disease (DOHaD)' hypothesis, a rather more recent term for the concept initially proposed and called 'Fetal Origins of Adult Disease' in the 1990s, ${ }^{1}$ postulates that exposure to certain environmental influences during critical periods of development and growth may have significant consequences on an individual's short- and long-term health. ${ }^{2}$ In this concept, the developing fetus, if exposed to a hostile uterine environment (caused by insults such as poor nutrition, infections, chemicals, metabolite or hormonal perturbations), ${ }^{3}$ responds by developing adaptations (predictive adaptive responses-PARs), that not only foster its immediate viability, but also its survival if a similar environment is encountered later in life. ${ }^{4,5}$ Some examples of shortterm adaptations the fetus may make in these scenarios include down-regulation of endocrine or metabolic function, and/or specific organ function to slow down its growth rate to match the nutrient supply in the deprived uterine environment. ${ }^{6}$ Long-term, subtle, irreversible changes in the development, structure and function of some tissues and vital organs (thymus, skeletal muscle, lungs, pancreas, kidney) may occur ${ }^{7}$ as a result of disruptions in gene expression, cell differentiation and proliferation. However, if the individual then grows up in an extra-uterine environment the reverse of that experienced in utero, the 'mismatch' and poorer fit, therefore, would predispose them to a higher risk of certain non-communicable diseases (NCDs). ${ }^{3}$ This risk is further exacerbated by excessive weight gain in postnatal/adult life, and by the aging process itself. ${ }^{5,8}$

\section{Manifestation of DOHaD}

Much of the evidence underpinning DOHaD science has been obtained from animal models and observational human studies. It shows that the period from conception to early childhood, i.e. prenatal development to child growth-when organogenesis and rapid growth are occurring ${ }^{9}$-is critical to the immediate and future health of the infant. Studies that looked at undernutrition acting in this early life period (as a result of either maternal undernutrition or protein/calorie restriction), ${ }^{4}$ showed that it not only retarded growth, ${ }^{10}$ but also induced lifelong changes in hormonal concentrations, and the sensitivity of various tissues to these fetal and placental hormones-alterations that lead to abnormal organ development ${ }^{11,12}$ and to diseases such as type-2 diabetes mellitus (T2DM), cardiovascular disease (CVD), kidney disease, obesity, hypertension, osteoporosis and metabolic syndrome in later life. ${ }^{13,14}$ These irreversible changes to tissue structure and physiology made to survive the harsh environment encountered in utero have also been called 'programming', and they are dependent on the nature and point at which exposure to the insult occurs, since tissues mature at different rates and time points. ${ }^{11,15}$ This differential effect is well illustrated with undernutrition, to which exposure too soon after conception, for example, slows down fetal growth and leads to low birthweight of the infant. In contrast, if undernutrition occurs during mid-pregnancy, it may alter placental development and lead to fetal wasting during the remainder of the

(c) The Author(s) 2018. Published by Oxford University Press Royal Society of Tropical Medicine and Hygiene.

This is an Open Access article distributed under the terms of the Creative Commons Attribution License (http://creativecommons.org/licenses/by/4.0/), which permits unrestricted reuse, distribution, and reproduction in any medium, provided the original work is properly cited. 
pregnancy-disturbances that can result in distinct metabolic phenotypes in adulthood. ${ }^{13}$ Exposure to various other environmental factors including maternal stress, infections, hypertension, obesity, teratogens, alcohol, drugs, cigarette smoke, over nutrition and paternal malnutrition, within these critical windows of growth and development, have also been associated with an increased risk of adult disease. ${ }^{16,17}$

\section{Underlying mechanisms}

The mechanisms that mediate the programming effects of diverse environmental insults, or how this memory is stored are unclear, but a few have been postulated. These include the following.

(1) Excessive exposure to glucocorticoids (GCs): GCs (stress hormones) are well known for their role in homeostasis (control of blood pressure and glucose metabolism) in adult life, but are also essential for fetal maturation. ${ }^{18}$ However, fetal GC load is normally regulated by $11 \beta$-hydroxysteroid dehydrogenase type-2 (11 $\beta$-HSD2), a placental enzyme that inactivates GCs. Exposing the fetus to high GC levels (by inhibiting $11 \beta$-HSD2 or bypassing it through administration of synthetic $\mathrm{GC}$ ) in rodents leads to growth retardation, and increases risk of glucose intolerance and high blood pressure in adulthood. ${ }^{18,19}$ Interestingly, other insults (notably maternal undernutrition) provoke a stress response (increasing maternal GC levels) and attenuate $11 \beta-H S D 2$ expression-potentially increasing fetal exposure to GCs. Thus, GCs may provide a common mechanism through which other insults exert their programming effects (illustrated in Figure 1 below).

(2) Dysregulation in the development of the hypothalamicpituitary-adrenal (HPA) axis: A number of environmental exposures during early life (such as maternal stress, infections, undernutrition or GC treatment) have been shown to permanently increase activity of the HPA axis. This may result from differential expression of the GC receptors, with reduced expression in the hypothalamus attenuating negative feedback and increasing GC production from the adrenal glands. Changes in the activity of this neuroendocrine system influence development and regulation of various organs, and homeostatic systems, such as the central nervous, cardiovascular and metabolic systems, pancreas, kidney and adipose tissue. This aberrant activity can ultimately lead to increased risk of cardiovascular disease and cardio-metabolic disorders in adulthood

(3) Irreversible changes in organ structure: Early life insults might also lead to permanent dysfunction and disease through irreversible changes in organ structure. For example, several insults such as undernutrition and hypoxia ${ }^{20}$ in utero have been associated with reduced nephron numbers (as a result of decreased nephrogenesis or renal progenitor cells), ${ }^{21}$ fewer pancreatic $\beta$-cell numbers/islet vascularization ${ }^{22}$ and liver lobules. The reduction in nephron numbers/function would increase risk of hypertension and renal disease, while reduced $\beta$-cell mass (as well as defective insulin signaling in skeletal muscle and adipose tissue), ${ }^{23}$ would dispose the individual to impaired glucose control in older age.

(4) Alterations in gene expression: A more recently suggested mechanism through which early exposures might mediate their long-term effects, involves epigenetics. ${ }^{3}$ Epigenetic modifications, which include DNA methylation, histone marks and non-coding RNAs, regulate gene expression independent of changes in the DNA sequence, and are important to normal development and differentiation. ${ }^{23}$ DNA methylation, for example, is vital to cell differentiation, carcinogenesis and genomic imprinting. ${ }^{24}$ A number of studies in animal models and humans have shown that prenatal insults such as undernutrition or GCs can influence epigenetic marks. For example, in utero exposure to famine during the Dutch Hunger Winter of 1944-45, showed that these individuals in adulthood, ${ }^{4}$ had reduced methylation at regulatory regions for the insulin-like growth factor II, a hormone critical to growth and development. ${ }^{25}$ Other studies also found undernutrition in utero to alter methylation rates of the key enzyme (11 $\beta$ HSD2) and hormonal receptor sites (GC receptors), changes that perturb hormone homeostasis and can lead to adult disease. ${ }^{26}$ Changes in non-coding RNA and histone modifications at genes of key transcription factors, such as the PPARs, Hnf $4 \alpha$ and $P d x 1$, critical to normal tissue and organ development (adipose tissue, the pancreas, liver), cellular differentiation and metabolism, have also been associated with aberrance and susceptibility to T2DM. $^{27}$

Other proposed mechanisms include genetics, ${ }^{28}$ cellular aging ${ }^{29}$ and intergenerational effects (exposures experienced by one generation that influence the health of the next, because they persist across generations or are genetic, or occur in utero and are self-perpetuating such as those that affect the HPA axis). ${ }^{30}$

\section{The impact on risk of NCDs: could DOHaD have a role?}

It is known now that NCDs can be caused by a number of factors including genetics, environmental, physiological and behavioral patterns, and that they can occur in all age groups even though they are primarily diseases of old age. ${ }^{31}$ NCDs are the current leading cause of death globally, accounting for about 40 million (70\%) deaths annually. ${ }^{31}$ They are generally attributed to four main risk factors: tobacco smoke, harmful alcohol consumption, poor diet and physical inactivity. ${ }^{31}$ However, these factors do not seem to fully explain the pattern of NCDs emerging in developing countries with the fast pace of urbanization, and consequent epidemiological and nutrition transitions. ${ }^{32,33}$ The epidemics in these regions seem to differ in some characteristics - with presentation occurring at a seemingly earlier age and disease progression at a faster rate than has been reported in developed countries; ${ }^{34,35}$ more than four-fifths of the estimated 15 million premature worldwide deaths from NCDs occur in these low- and middle income settings. ${ }^{31}$ These differences raise the question as to whether there are other drivers of chronic disease in these regions and the argument that there may well be. ${ }^{36} \mathrm{~A}$ proportion of NCDs in less developed resource-constrained countries could probably be explained by other factors, particularly, ${ }^{4}$ the encounter of adverse experiences during critical periods of growth (prenatal, childhood and in adolescence). ${ }^{32}$

Evidence from the numerous studies cited above would strongly support this notion, highlighting the need to further 


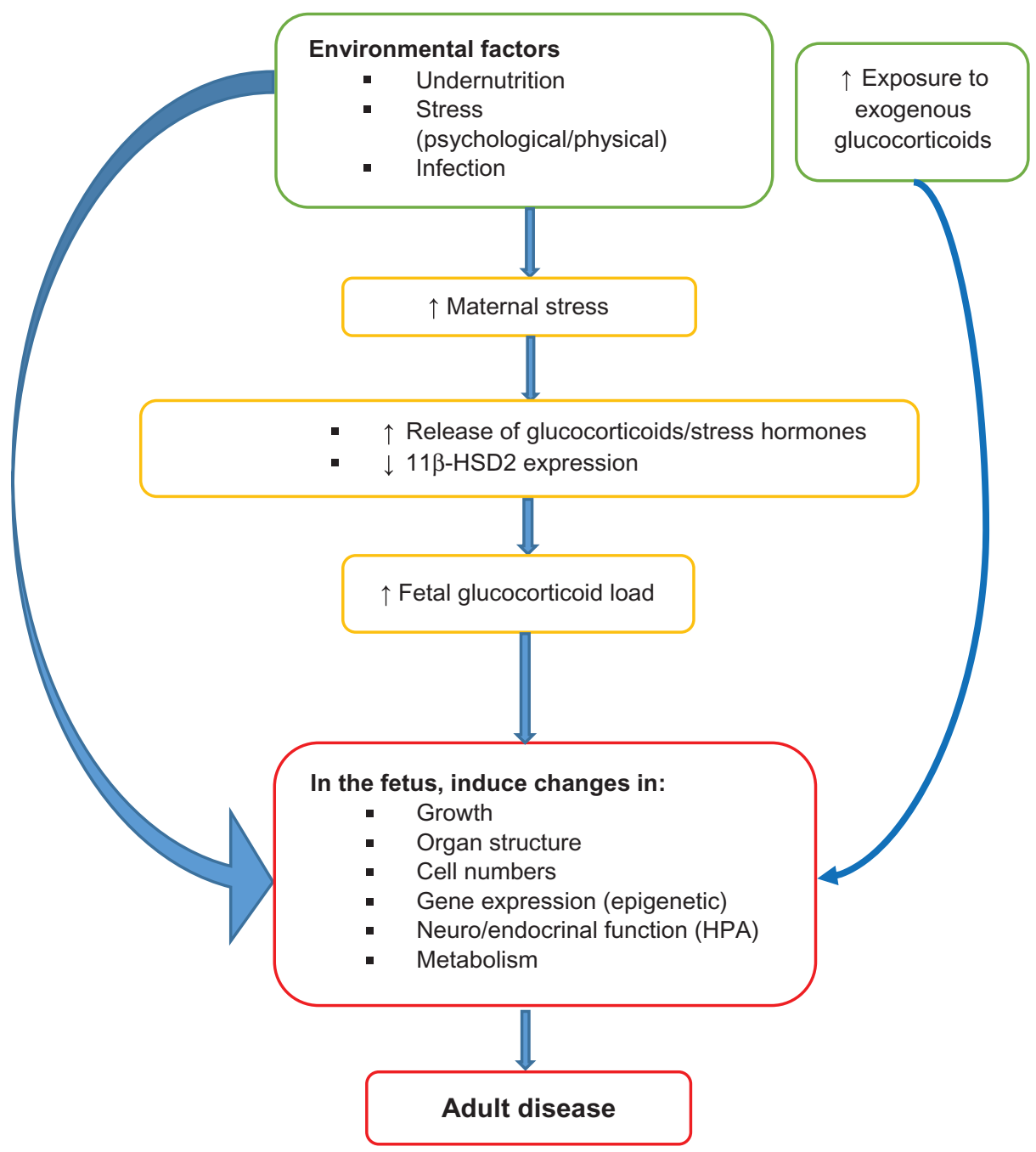

Figure 1. A theory of glucocorticoids as a potential common mechanism through which various environmental factors exert their programming effects.

understand the role DOHaD may have in driving the NCD epidemic, and how it could contribute to the design of appropriate interventions, to address this growing public health problem, ${ }^{32}$ especially given that it is in these same regions that poverty, malnutrition, infections, low birth weight and poor sanitation are still prevalent. DOHaD science would be particularly useful for informing ways to improve nutrition and not just in early life, where fetal malnutrition, largely a consequence of poor maternal nutrition, has been shown to alter normal patterns of growth and development, ${ }^{37}$ but throughout the life course. ${ }^{38}$ Presently, about one-third of the world's population, mostly in developing countries, suffers from some form of malnutrition; 815 million from calorie deficiency and nearly 2 billion from being overweight or obese. ${ }^{39}$ This year alone, maternal and child undernutrition accounted for $10 \%$ of the global burden of disease $^{40}$ and obesity for about 2.8 million deaths. ${ }^{41}$ Together with other, often related NCDs, these represent a significant burden of ill health and put enormous strain not just on individuals and their families, but also on the health systems, societies and economies of these nations. ${ }^{42}$ Knowing this, it is imperative to step up the momentum to tackle these problems where effort is already being made, an even more importantly, to garner attention, as well as begin to utilize what knowledge of DOHaD we have, in regions where little is understood or being done. ${ }^{34}$

In conclusion, we now know that it is possible to reduce the burden of NCDs and to have an impact on long-term health outcomes by using approaches that address the influence of environmental factors on growth and development. Because these, unlike genetics or aging (important causes of NCDs), can be modified, they provide an opportunity, using the knowledge there is of developmental plasticity, to design interventions that could prevent many of these chronic diseases. ${ }^{16}$ However, like all previous successes, HIV-AIDs the classic one, progress addressing NCDs will require the political will, and NCDs getting on the national agendas, especially those of countries in the developing regions.

As for the next steps and interventions, it is critical that these take a life-course as well as a multi-disciplinary approach to be able to affect multiple generations. ${ }^{31,34,43,44} \mathrm{~A}$ few to consider include: 
- Reducing poverty: which would improve living standards and health outcomes because it would reduce the risk of malnutrition, ${ }^{3,44}$ infections ${ }^{32}$ and disease.

- Investing in nutrition: to improve access, availability and affordability of nutritious foods. ${ }^{45}$

- Education: on the importance of nutrition and physical activityusing mass media for the general public and by integrating the subjects into science syllabi for primary and secondary school.

- Promoting breast feeding, and healthy infant and young child feeding practices. ${ }^{44}$

- Improving practices/access to water, sanitation and hygiene.

- Supporting strategies to reduce tobacco smoking and alcohol consumption. $^{42}$

- Addressing gender inequity so that females are empowered to make better decisions for themselves and their families, the children particularly. ${ }^{44}$

Author's contributions: $M N$ conceived the idea for the paper; MM drafted it; $M N$ critically revised the paper for intellectual content and presentation.

Acknowledgements: The authors would like to thank Professor Robert Newton for his insightful input reviewing the paper.

Funding: None.

Competing interests: None declared.

Ethical approval: Not required.

\section{References}

1 Hales CN, Barker DJ, Clark PM et al. Fetal and infant growth and impaired glucose tolerance at age 64. Br Med J 1991;303(6809): 1019-22.

2 Barker DJ. The origins of the developmental origins theory. J Intern Med 2007;261(5):412-17.

3 Gluckman PD, Hanson MA, Cooper C et al. Effect of in utero and early-life conditions on adult health and disease. N Engl J Med 2008; 359(1):61-73.

4 Gluckman PD, Hanson MA, Spencer HG. Predictive adaptive responses and human evolution. Trends Ecol Evol 2005;20(10):527-33.

5 Hales CN, Barker DJ. The thrifty phenotype hypothesis. Br Med Bull 2001;60(1):5-20.

6 Osmond C, Barker DJ, Winter PD et al. Early growth and death from cardiovascular disease in women. $\mathrm{Br}$ Med J 1993;307(6918): 1519-24.

7 Barker DJ, Forsén T, Uutela A et al. Size at birth and resilience to effects of poor living conditions in adult life: longitudinal study. $\mathrm{Br}$ Med J 2001;323(7324):1273-6.

8 Vickers MH, Breier BH, Cutfield WS et al. Fetal origins of hyperphagia, obesity, and hypertension and postnatal amplification by hypercaloric nutrition. Am J Physiol Endocrinol Metab 2000;279(1):E83-7.
9 Painter RC, Roseboom TJ, Van Montfrans GA et al. Microalbuminuria in adults after prenatal exposure to the Dutch famine. J Am Soc Nephrol 2005;16(1):189-94.

10 Widdowson EM, Crabb DE, Milner RD. Cellular development of some human organs before birth. Arch Dis Child 1972;47(254):652-5.

11 Langley-Evans SC, McMullen S. Developmental origins of adult disease. Med Princ Pract 2010;19(2):87-98.

12 Tarry-Adkins $\mathrm{JL}$, Chen $\mathrm{JH}$, Jones $\mathrm{RH}$ et al. Poor maternal nutrition leads to alterations in oxidative stress, antioxidant defense capacity, and markers of fibrosis in rat islets: potential underlying mechanisms for development of the diabetic phenotype in later life. FASEB J 2010;24(8):2762-71.

13 Barker DJ, Godfrey KM, Gluckman PD et al. Fetal nutrition and cardiovascular disease in adult life. Lancet 1993;341(8850):938-41.

14 Kensara OA, Wootton SA, Phillips DI et al. Fetal programming of body composition: relation between birth weight and body composition measured with dual-energy X-ray absorptiometry and anthropometric methods in older Englishmen. Am J Clin Nutr 2005;82(5):980-7.

15 Bateson P, Barker D, Clutton-Brock T et al. Developmental plasticity and human health. Nature 2004;430(6998):419-21.

16 Heindel JJ, Vandenberg LN. Developmental origins of health and disease: a paradigm for understanding disease etiology and prevention. Curr Opin Pediatr 2015;27(2):248-53.

17 Mamun AA, O'Callaghan MJ, Williams GM et al. Maternal smoking during pregnancy predicts adult offspring cardiovascular risk factorsevidence from a community-based large birth cohort study. PLoS One 2012;7(7):e41106.

18 Nyirenda MJ, Lindsay RS, Kenyon CJ et al. Glucocorticoid exposure in late gestation permanently programs rat hepatic phosphoenolpyruvate carboxykinase and glucocorticoid receptor expression and causes glucose intolerance in adult offspring. J Clin Invest 1998;101 (10):2174-81.

19 Lindsay RS, Lindsay RM, Waddell BJ et al. Prenatal glucocorticoid exposure leads to offspring hyperglycaemia in the rat: studies with the 11 b-hydroxysteroid dehydrogenase inhibitor carbenoxolone. Diabetologia 1996;39(11):1299-305.

20 Camm EJ, Martin-Gronert MS, Wright NL et al. Prenatal hypoxia independent of undernutrition promotes molecular markers of insulin resistance in adult offspring. FASEB J 2011;25(1):420-7.

21 Woods LL, Weeks DA, Rasch R. Programming of adult blood pressure by maternal protein restriction: role of nephrogenesis. Kidney Int 2004;65(4):1339-48.

22 Remacle C, Dumortier O, Bol V et al. Intrauterine programming of the endocrine pancreas. Diabetes, Obes Metab 2007;9(s2):196-209.

23 Martin-Gronert MS, Ozanne SE. Mechanisms underlying the developmental origins of disease. Rev Endocr Metab Disord 2012;13(2): 85-92.

24 Jaenisch R, Bird A. Epigenetic regulation of gene expression: how the genome integrates intrinsic and environmental signals. Nat Genet 2003;33(3s):245-54.

25 Heijmans BT, Tobi EW, Stein AD et al. Persistent epigenetic differences associated with prenatal exposure to famine in humans. Proc Natl Acad Sci USA 2008;105(44):17046-9.

26 Drake AJ, McPherson RC, Godfrey KM et al. An unbalanced maternal diet in pregnancy associates with offspring epigenetic changes in genes controlling glucocorticoid action and foetal growth. Clin Endocrinol (Oxf) 2012;77(6):808-15.

27 Ferland-McCollough D, Fernandez-Twinn DS, Cannell IG et al. Programming of adipose tissue miR-483-3p and GDF-3 expression 
by maternal diet in type 2 diabetes. Cell Death Differ 2012;19(6): 1003-12.

28 Hattersley AT, Beards F, Ballantyne E et al. Mutations in the glucokinase gene of the fetus result in reduced birth weight. Nat Genet 1998;19(3):268-70.

29 Chen JH, Hales CN, Ozanne SE. DNA damage, cellular senescence and organismal ageing: causal or correlative? Nucleic Acids Res 2007;35(22):7417-28.

30 Drake AJ, Walker BR. The intergenerational effects of fetal programming: non-genomic mechanisms for the inheritance of low birth weight and cardiovascular risk. J Endocrinol 2004;180(1):1-16.

31 WHO. Noncommunicable diseases; 2017. http://www.who.int/ mediacentre/factsheets/fs355/en/ [accessed 21 September 2017].

32 Moore SE. Early life nutritional programming of health and disease in the Gambia. J Dev Orig Health Dis 2016;7(2):123-31.

33 WHO. Global health risks; 2009. http://www.who.int/healthinfo/global burden_disease/global_health_risks/en/ [accessed 25 September 2017].

34 Gluckman PD, Hanson MA, Mitchell MD. Developmental origins of health and disease: reducing the burden of chronic disease in the next generation. Genome Med 2010;2(2):14.

35 WHO. Preventing chronic diseases: a vital investment; 2005. http:// www.who.int/chp/chronic_disease_report/contents/en/ [accessed 12 October 2017].

36 Miranda JJ, Kinra S, Casas JP et al. Non-communicable diseases in low- and middle-income countries: context, determinants and health policy. Trop Med Int Health 2008;13(10):1225-34.
37 Winick $M$, Noble A. Cellular response in rats during malnutrition at various ages. J Nutr 1966;89(3):300-6.

38 Uauy R, Kain J, Corvalan C. How can the Developmental Origins of Health and Disease (DOHaD) hypothesis contribute to improving health in developing countries? Am J Clin Nutr 2011;94(6 Suppl.): 1759S-64S.

39 FAO. World hunger on the rise; 2017. http://www.fao.org/state-offood-security-nutrition/en/?utm_source=WHO+List\&utm_campaign= f3285c565f-EMAIL_CAMPAIGN_2017_09_15\&utm_medium=email\& utm_term $=0 \_823 \bar{e} 9$ e35c1-f3285c5̄ $65 \bar{f}-266691637$ [accessed 19 September 2017].

40 WHO. 10 facts on nutrition; 2017. http://www.who.int/features/ factfiles/nutrition/en/ [accessed 21 September 2017].

41 WHO. 10 Facts on Obesity; 2017. http://www.who.int/features/ factfiles/obesity/en/ [accessed 6 October 2017].

42 WHO. From burden to 'best buys': reducing the economic impact of non-communicable diseases in low- and middle-income countries; 2011. http://www.who.int/nmh/publications/best_buys_summary.pdf [accessed 11 October 2017].

43 Norris SA, Daar A, Balasubramanian D et al. Understanding and acting on the developmental origins of health and disease in Africa would improve health across generations. Glob Health Action 2017; 10(1):1334985.

44 WHO. Promoting optimal fetal development: report of a technical consultation. Geneva: World Health Organisation; 2006.

45 Diet, nutrition and the prevention of chronic diseases: report of a joint WHO/FAO expert consultation; 2003. 